This item was submitted to Loughborough's Research Repository by the author.

Items in Figshare are protected by copyright, with all rights reserved, unless otherwise indicated.

\title{
Investigation of thermal degradation and decomposition of both pristine and damaged carbon/epoxy samples with thermal history
}

PLEASE CITE THE PUBLISHED VERSION

https://doi.org/10.1016/j.compositesb.2020.108382

PUBLISHER

Elsevier

VERSION

AM (Accepted Manuscript)

\section{PUBLISHER STATEMENT}

This paper was accepted for publication in the journal Composites Part B: Engineering and the definitive published version is available at https://doi.org/10.1016/j.compositesb.2020.108382

LICENCE

CC BY-NC-ND 4.0

\section{REPOSITORY RECORD}

Zhou, Gang, Ewa Mikinka, James Golding, Xujin Bao, W Sun, and A Ashby. 2020. "Investigation of Thermal Degradation and Decomposition of Both Pristine and Damaged Carbon/epoxy Samples with Thermal History". Loughborough University. https://hdl.handle.net/2134/12933089.v1. 


\title{
Investigation of thermal degradation and decomposition of both pristine and damaged carbon/epoxy samples with thermal history
}

\author{
G. Zhou ${ }^{* 1}$, E. Mikinka ${ }^{1}$, J. Golding ${ }^{1}$,X. Bao ${ }^{2}$, W. Sun $^{3}$ and A. Ashby ${ }^{1}$ \\ ${ }^{1}$ Department of Aeronautical and Automotive Engineering, Loughborough University, \\ Loughborough LE11 3TU, UK \\ ${ }^{2}$ Department of Materials, Loughborough University, Loughborough LE11 3TU, UK \\ ${ }^{3}$ C-Power Ltd, No 5 Huake Si Road, Tianjing, China
}

\begin{abstract}
Although the investigation of thermal damage in composite materials has increased, the short-term thermal degradation and decomposition mechanisms in a non-oxidative environment have not been well established, as the reported thermal damage results were heavily influenced by the analyses of delicately collected volatiles and the presence of oxygen. The aim of this study, using scanning electron microscopy, Fourier transform infrared spectroscopy and thermogravimetry, along with kinetics, was to develop a post-mortem solid residual-based microscopic characterising methodology for thermal damage in carbon/epoxy composites induced by simulated lightning strikes. Fibre tufting, resin sublimation and discolouration were found to represent the severity of damage in three damage zones. Whilst fibre tufting was caused not by thermal sublimation but by returning shock waves, resin sublimation and discolouration were dominated by Joule heating. The carbon concentration in the damaged zones was found to radially decrease outwards and vice versa with oxygen. Decomposition started from epoxy dehydration, accompanied by discolouration and formation of water and carbonyl, and released chemical compounds like 2-propenal, acetylene and carbonylcontaining aromatic ether. The successful identification of these unique heating-formed functional groups provided the confirmation of the proposed methodology.
\end{abstract}

Key words: carbon/epoxy, TGA, thermal damage, thermal degradation, decomposition mechanisms

\section{Introduction}

Carbon/epoxy composite materials are lightweight and have excellent specific strength and stiffness, along with good corrosion resistance and are often used in large modern structural systems such as aircraft and wind turbine blades. Despite their remarkable qualities, carbon/epoxy composites are anisotropic with limited thermal conductivities. Under intensive thermal heating, these attributes lead not only to complex thermal behaviours but also to damage characteristics, which are completely different from those driven by mechanical stresses. These challenging scenarios arise in the engineering fields of lightning strike [1-2], laser processing [3-4], fire combustion [5-6] and composites recycling [7]. To achieve the long-term benefits, the thermal degradation processes and decomposition mechanisms of composite materials must be thoroughly understood so that the resulting data and knowledge can be used in the development of a damage characterisation methodology, thereby contributing to an assessment of their residual performance. Achieving such a goal requires thermal degradation mechanisms to be identified, ascertained and characterised in terms of temperature and other thermal heating parameters through an investigation of solid residual composite materials. These investigation tasks become forensic in nature and hence are tremendously challenging. They are often compounded by the fact that chemical compositions of commercial composite materials are unavailable due to commercial sensitivities.

\footnotetext{
*Author to whom any correspondence should be addressed. G.Zhou@Lboro.ac.uk.
} 
The thermal degradation and decomposition processes of solid polymers are studied not only experimentally using Thermogravimetric Analysis (TGA) but also analytically through kinetic reaction models [8-9]. As the most popular technique for non-isothermal conditions, TGA can generate thermal degradation details and parameter data, which enable the development of kinetic reaction models. To ascertain thermal decomposition mechanisms, Fourier Transform Infrared with Attenuated Total Reflection (FTIR-ATR) and Scanning Electron Microscope with Energy Dispersion Spectroscopy (SEM-EDS) provide a vital aid. For composite materials, combined techniques of TGA with non-destructive SEM-EDS and FTIR-ATR are essential to the development of a post-mortem thermal damage evaluation methodology on a basis of solid residual composite materials.

The present work reports the results of an investigation of thermal degradation and decomposition of commercial carbon/epoxy (DGEBA/DDM) composite materials. Six carbon/epoxy panels were thermally damaged under simulated lightning strikes with a range of electrical lightning energies. Multiple locations selected from different damage zones with varying thermal conditions on each damaged panel were examined non-destructively using SEM-EDS and FTIR-ATR to determine delicate changes undergone in chemical composition and functional groups. Samples extracted from the examined locations were then tested destructively using TGA under non-isothermal conditions with various heating rates. The kinetic parameters were determined using both Kissinger and FlynnWall-Ozawa (FWO) methods. The thermal characteristics of the degradation process were examined through systematic damage state comparisons of damage locations on the same panels and the same locations from different panels. This is the first time that the thermal decomposition mechanisms of commercial carbon/epoxy composites were forensically reconstructed on a basis of solid residual composite materials.

\section{Materials and sample preparations}

Carbon/epoxy laminates were made of LTM45/34-700 fabric prepreg in plain weave with a nominal ply thickness of $0.4375 \mathrm{~mm}$. They were laid up to have the dimensions of $300 \times 300 \mathrm{~mm}$ in a lay-up of cross ply (CP) and were cured in an autoclave at $65^{\circ} \mathrm{C}$ under a pressure of $0.62 \mathrm{MPa}$ (90 psi) for 16 hours to have a nominal thickness of $3.2 \mathrm{~mm}$. The $34-700$ carbon fibres are PAN-based. The LTM45 epoxy resin was formulated with diglycidyl ether bisphenol A (DGEBA), bisphenol A, formaldehyde, 4,4'-methylenedianiline (MDA), 2-ethyl-4-methyl-1H-imidazole-1-propiononitrile and 2-ethyl-4-methyl-imidazole. The molecular structures of both DGEBA and MDA (or DDM) of this epoxy resin are shown respectively in Figures $1 \mathrm{a}$ and 1b. (A recurring segment of cured DGEBA-MDA epoxy can also be seen from the upper part in Figure 16.)<smiles>CCC(Oc1ccc(C(C)(C)c2ccc(OCC(O)COc3ccc(C(C)(C)c4ccc(OCC5CO5)cc4)cc3)cc2)cc1)C1CO1</smiles>

Figure 1a Molecular structure of diglycidyl ether bisphenol A (DGEBA) monomer.<smiles>Nc1ccc(C=Cc2ccc(N)cc2)cc1</smiles>

Figure 1b 4,4'-methylenedianiline (MDA). 
Each of six laminate panels with the dimensions of $150 \times 100 \mathrm{~mm}$ was subjected to a simulated lightning strike at the centre at a normal incidence with an electrode gap of $3 \mathrm{~mm}$ using a solid conical copper electrode of $10 \mathrm{~mm}$ shaft diameter. A variety of severities of thermal damage states was generated intentionally through the variation of input peak electric currents and was characterised qualitatively by fibre tufting (or breakage), resin sublimation with fibre filaments exposed at fibre cross-overs and resin discolouration. Test results are summarised in Table 1 and an example of the tested panels is shown in Figure 2. Whilst Panels 3-1 and 3-2 exhibited only resin sublimation exposing fibre filaments at fibre cross-overs and resin discolouration, the rest of the panels all had fibre tufting at their respective central areas.

Table 1 Lightning strike test details on carbon/epoxy panels

\begin{tabular}{cccccc}
\hline $\begin{array}{c}\text { Panel } \\
\text { ID } \\
-\end{array}$ & $\begin{array}{c}\text { Peak } \\
\text { current } \\
\mathrm{kA}\end{array}$ & $\begin{array}{c}\text { Charge } \\
\text { transfer } \\
\text { Coulomb }\end{array}$ & $\begin{array}{c}\text { Action } \\
\text { integral } \\
\mathrm{A}^{2} \mathrm{~s}\end{array}$ & $\begin{array}{c}\text { Surface } \\
\text { damage area } \\
\mathrm{mm}^{2}\end{array}$ & $\begin{array}{c}\text { Area of } \\
\text { fibre tufting } \\
\mathrm{mm} \times \mathrm{mm}\end{array}$ \\
\hline $3-1$ & 6.39 & 0.111 & 622 & 38.26 & - \\
$3-2$ & 11.87 & 0.197 & 2012 & 71.94 & - \\
$3-3$ & 21.38 & 0.360 & 6471 & 129.58 & $6 \times 6$ \\
$3-4$ & 41.31 & 0.847 & 37242 & 393.43 & $8 \times 8$ \\
$3-5$ & 60.95 & 1.010 & 52985 & 369.39 & $20 \times 20$ \\
$3-6$ & 90.10 & 1.490 & 115925 & 542.77 & $20 \times 20$
\end{tabular}

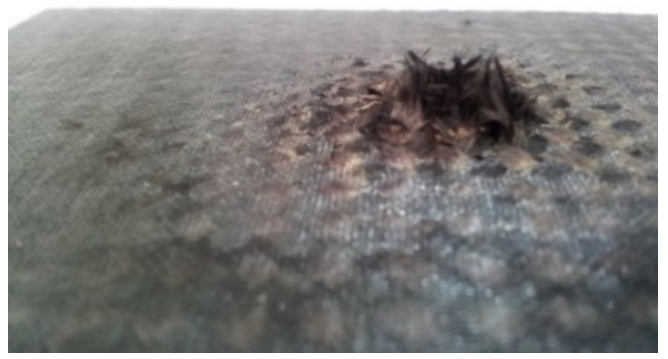

Figure 2 Carbon/epoxy Panel 3-6 struck by a lightning current of 90kA.

Seven equally-spaced locations on each tested panel were selected to represent all the identified damage characteristics. From each location, as indicated in Figure 3, a truncated inclined rectangular block (a dashed frame) was extracted and symmetrically split through the laminate thickness to produce four quarter TGA samples. Splitting was carried out by a hand-held Dremel 3000 with a circular blade of $0.6 \mathrm{~mm}$ thickness. Nominal planar dimensions of each sample were $3 \times 3 \mathrm{~mm}$ and a dimensional precision of the samples was unimportant to TGA tests. Sample weights varied from 23 to $58 \mathrm{mg}$ with the average being $45 \mathrm{mg}$ due to losses associated with fibre sublimation and resin sublimation. Although six damaged panels had different damage characteristics and different areas, all pristine samples on six panels were obtained from Locations 6 and 7, which were undamaged. The so-organised TGA samples not only covered all the damaged zones in each panel but could also differentiate between the thermal damage severity of the same locations from panel to panel.

\section{Methods and procedures}

The SEM model of Zeiss 1530VP was used to examine the surface morphologies of selected locations on all the panels. The coupled EDS allowed an element analysis of the samples to be conducted for the concentrations of elements such as carbon and oxygen within the composite material. Then FTIR spectra using a Shimadzu FTIR-8400S Analyser in ATR mode with a diamond crystal were obtained between 600 and $4000 \mathrm{~cm}^{-1}$, with an accumulated average of 64 scans over a round area of about $1 \mathrm{~mm}$ diameter with a resolution of $4 \mathrm{~cm}^{-1}$. Because the uneven surface 
topologies of the damaged samples were associated with the different damage characteristics from location to location, identical levels of contact pressure could not be guaranteed and so the moderate peak differences in intensity were not pursued. TGA tests using a TGA Q5000IR in nitrogen were carried out at the heating rates of 5,10 and $20^{\circ} \mathrm{C} / \mathrm{min}$, with a purge gas flow rate of $50 \mathrm{~mL} / \mathrm{min}$. Similar TGA tests were also performed in air at the heating rate of $20^{\circ} \mathrm{C} / \mathrm{min}$. Since the damaged samples contained a variation of lightning Joule-heating thermal histories, their delicate effects could be exposed through the TGA thermal decomposition process. The outcomes of this solid residualfocused methodology should provide a physical insight into the thermal decomposition mechanisms. SEM-EDS images, FTIR-ATR spectra and TGA data obtained from the undamaged samples from Locations 6 and 7 of all six panels were checked for consistency and repeatability (see Figures 11a and $11 \mathrm{~b}$, and Figures 13 and 14).

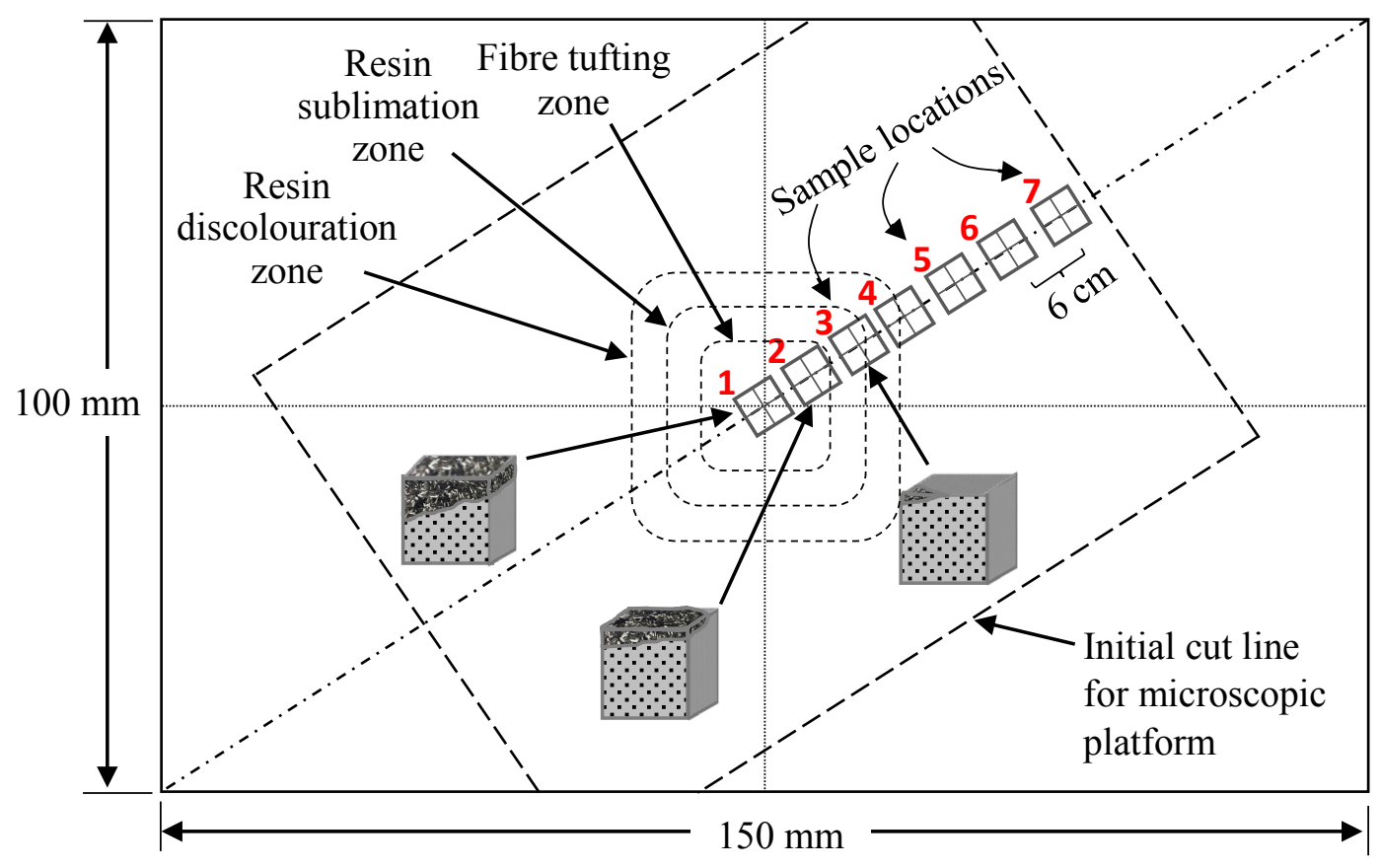

Figure 3 Illustration of locations and damage states for TGA samples.

\section{Thermal decomposition kinetics}

The weight losses (or conversion) of carbon/epoxy composite samples in TGA, as defined in Eq. (1), correspond to the evapouration of small epoxy fragments broken off due to the chain scission of their molecular bonds in the thermal decomposition process [10]:

$$
\alpha=\frac{m_{0}-m_{T}}{m_{0}-m_{\infty}}
$$

where $m_{0}, m_{\infty}$ and $m_{T}$ denote the initial and final masses as well as the mass at temperature $T$, respectively. This temperature-dependent reaction for polymeric composites can be assumed to be single-step [10] and hence the rate of reaction $k$ is defined by the Arrhenius equation [8] as

$$
k=A e^{-\frac{E_{a}}{R T}}
$$

where $A, E_{a}$ and $R$ are the pre-exponential factor, the activation energy and the molar gas constant $(8.314 \mathrm{~J} / \mathrm{mol})$, respectively. Both isothermal and non-isothermal reaction rates are described respectively by 


$$
\begin{aligned}
& \frac{\mathrm{d} \alpha}{\mathrm{d} t}=A e^{-\frac{E_{a}}{R T}}(1-\alpha)^{n} \\
& \frac{\mathrm{d} \alpha}{\mathrm{d} T}=\frac{A}{\beta} e^{-\frac{E_{a}}{R T}}(1-\alpha)^{n} \text { or } \frac{\mathrm{d} \alpha}{(1-\alpha)^{n}}=\frac{A}{\beta} e^{-\frac{E_{a}}{R T}} d T
\end{aligned}
$$

where $t, \beta$ and $n$ are time, linear heating rate and reaction order constant, respectively. The nonisothermal reaction rate is characterised by the activation energy $E_{a}$, the pre-exponential factor $A$ and the reaction order constant $n$ in addition to heating rate. The value of the order constant could commonly be evaluated on a basis of TGA data fitting.

For a single-step reaction, both model-free Kissinger and FWO methods were commonly used to determine the kinetic parameters of carbon/epoxy composites under various conditions. Close observations on the shapes of current TGA thermographs in Figures 4 and 5 supported the single-step reaction assumption, as the TGA thermograph shapes are visually closer to the 'sharp-sharp' characteristics, as defined in [11]. The Kissinger method [8] that uses the maximum temperatures $T_{m}$ of the first derivative weight fraction curves from TGA tests was obtained by differentiating Eq. (3a) with respect to $t$, setting the resulting expression to zero and taking the natural logarithms, as given by

$$
\ln \left(\frac{\beta}{T_{\max }^{2}}\right)=\ln \left(\frac{A R}{E_{a}} \cdot n(1-\alpha)^{n-1}\right)-\frac{E_{a}}{R T_{\max }}
$$

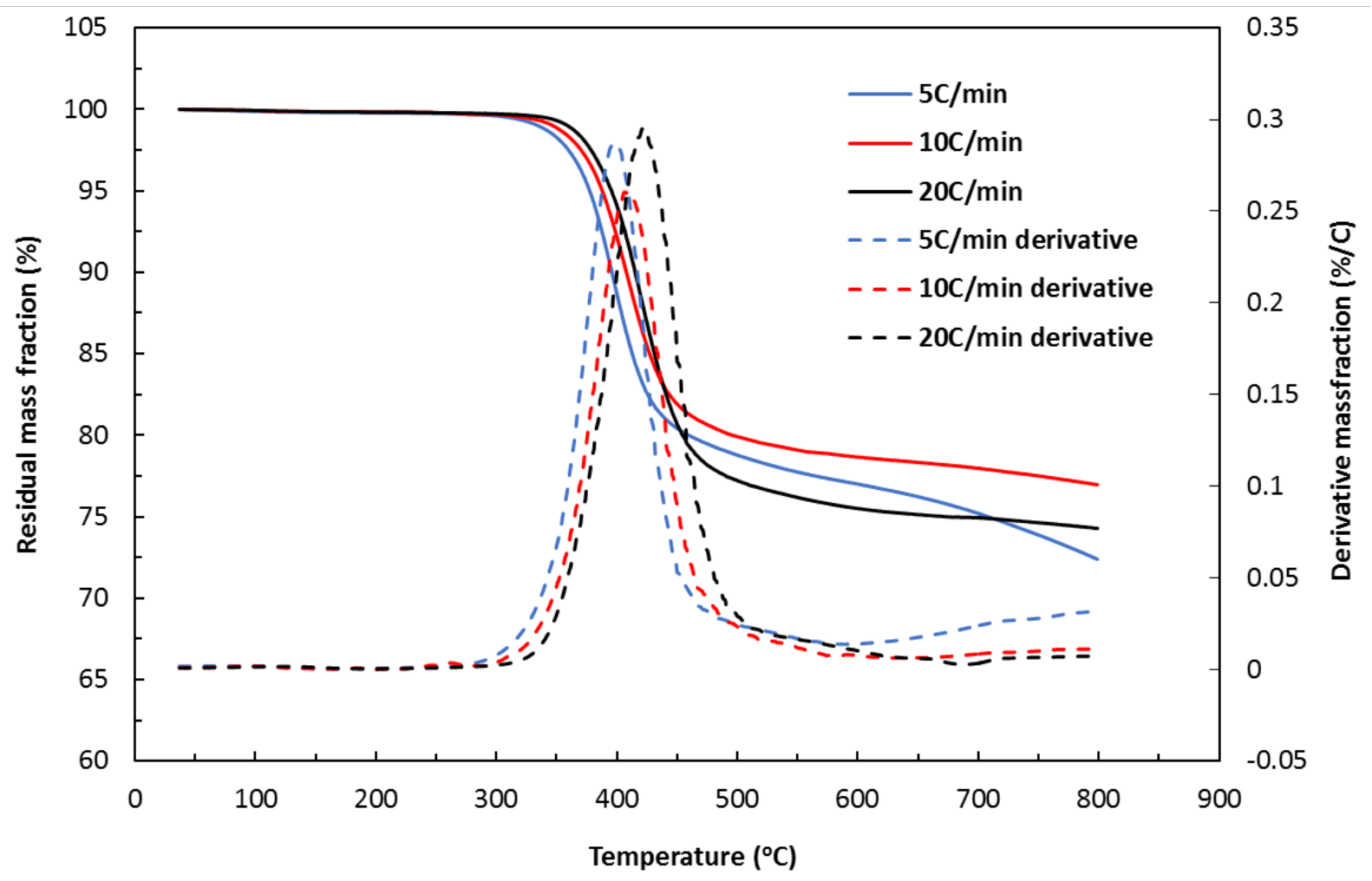

Figure 4 TGA thermograms of Location 4 samples of Panel 3-3 in nitrogen.

A slope of the best fit lines through three points in the coordinates of the $1 / T_{m}$ versus $\ln \left(\beta / T_{m}{ }^{2}\right)$ plot shown in Figure 6 yielded the average value of activation energy of $61.2 \mathrm{~kJ} / \mathrm{mol}$ for the composite material, with the intercept to the latter coordinate being the value of 92998 per second for the preexponential factor $A$. The value of the order constant in this approach of TGA data representation 
was implicitly assumed to be of the first order. Similarly, the isoconversional FWO method was obtained by taking the natural logarithmic of Eq. (3b) and approximating the integration, as given by

$$
\ln \beta=\left[\ln \left(\frac{A E_{a}(1-\alpha)^{n}}{R}\right)-5.33\right]-\frac{1.052 E_{a}}{R T}
$$

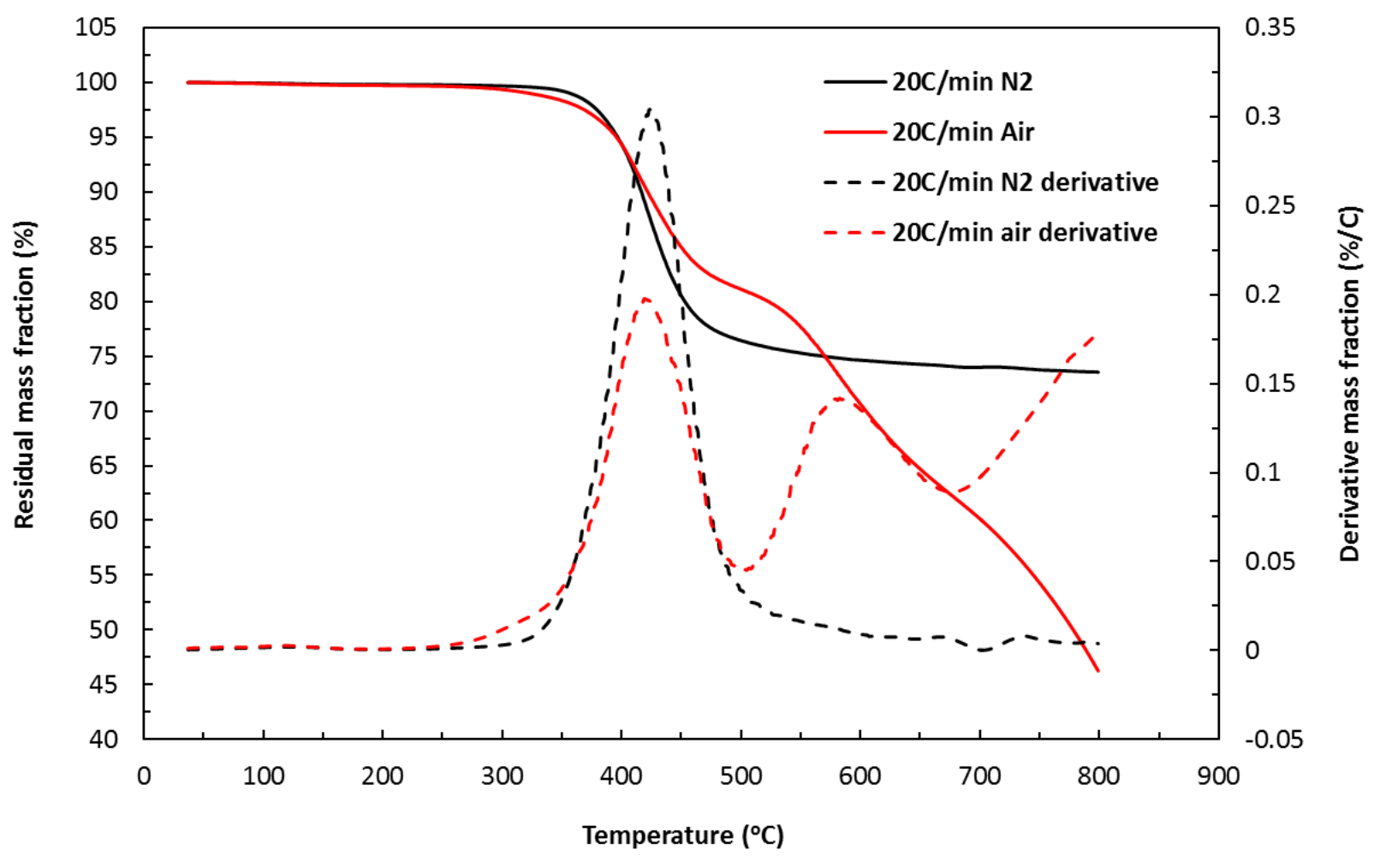

Figure 5 TGA thermograms from Location 2 samples of Panel 3-6.

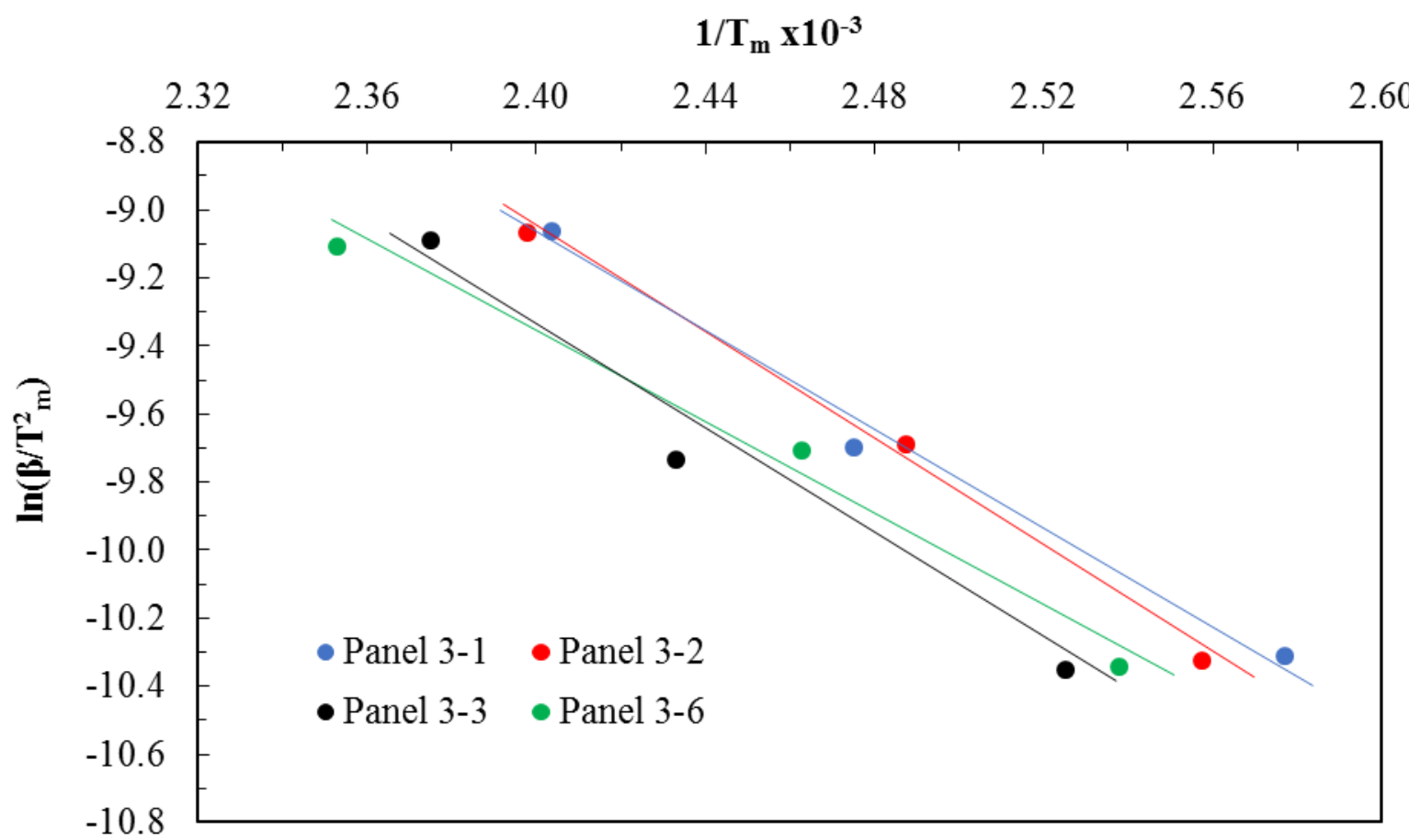

Figure 6 Kissinger method plots of carbon/epoxy samples from undamaged Location 7. 
Again, a slope and an intercept of the best linear fit lines from the $1 / T_{m}$ versus $\ln (\beta)$ plot obtained using different heating rates shown in Figure 7 allows the average value of $64.4 \mathrm{~kJ} / \mathrm{mol}$ for activation energy $E_{a}$ to be determined. The difference of the activation energy values between the two methods is very small.

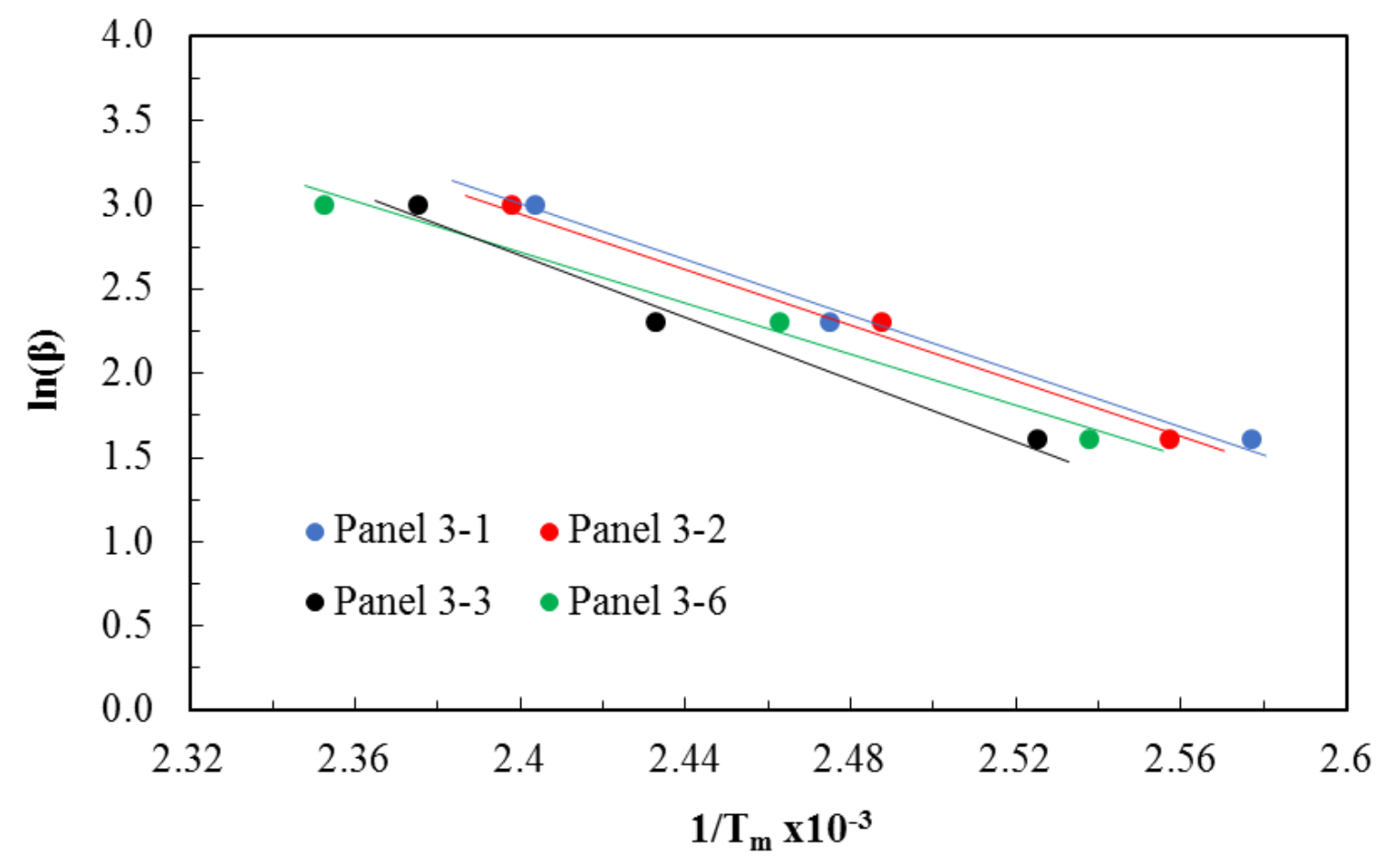

Figure 7 FWO method plots of carbon/epoxy samples from undamaged Location 7.

\section{Results and discussion}

\subsection{Non-destructive diagnostic observations of thermal damage}

The identified damage characteristics such as fibre tow breakage, fibre exposure with sublimated resin and resin discolouration on the lightning-damaged panels shown in Figure 2 were categorised in three damage zones, as shown in Figure 8 (also illustrated in Figure 3). As Panels 3-1 and 3-2 were subjected to the lower lightning strike currents of the range, only the latter two mechanisms were found. While the fibre-dominated mechanisms were easy to establish, resin discolouration in the outer annual region of the zone was estimated, sometimes with the aid of an optical microscope. Ascertaining the nature of fibre breakage and resin discolouration was very important to the thermal degradation process and to the subsequent residual performance evaluation, though the border line between the discoloured and normal resin was slightly difficult to detect.

The four micrographs shown in Figures 9a-9d were: from the two fibre tufting-dominated damage zones (Locations 1 and 2, see Figure 3); from the transitional region between fibre-exposed and resin discolouration zones (Location 4); along with an undamaged area (Location 6). The image of clean broken filament ends in Figure 9a indicates clearly that these filaments of the fibre tows were primarily pulled apart mechanically by the returning shock waves, rather than due to Joule heatingdominated fibre sublimation. It can also be observed that the relatively clean shafts of these filaments suggest that the resin pre-impregnated with these filaments was sublimated before such mechanical action had occurred to the top one or two plies within the zone. An enlarged end of the lower-left filament shown on its right with lots of pits on the shaft (in insert in 9a) indicates that the silane coating of some sections of the filaments could have been stripped off by resin sublimation. From Location 2 of the same zone, which is a couple of millimetres away from the central area in Figure 
$9 \mathrm{~b}$, significantly more resin clump residues can be observed on the filament shafts due to the relatively lower temperatures. Further away from the zone of the fibre-exposure by sublimated resin at Location 4 in Figure 9c, the transitional region was captured, where partially sublimated resin is clearly shown. The smooth contours of resin reflect the typical result of the thermal heating and this is in a sharp contrast to the image shown in Figure 9d from an undamaged area.

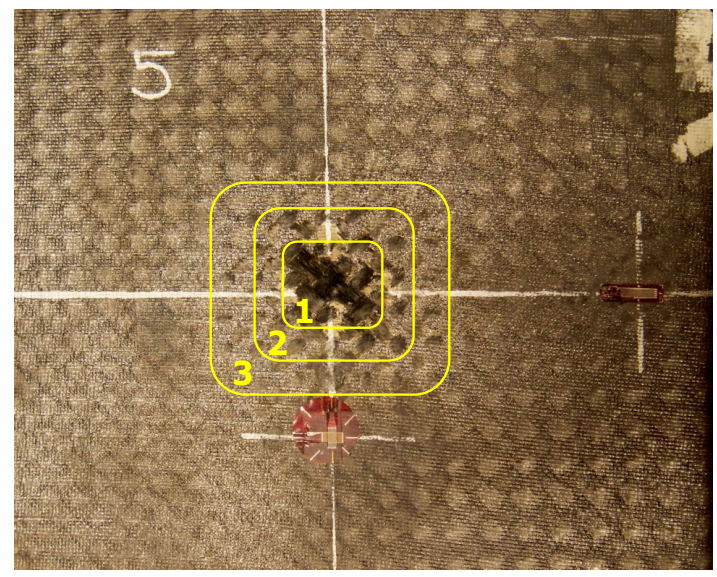

Figure 8 Damage zones generated by thermal heating and shock waves.

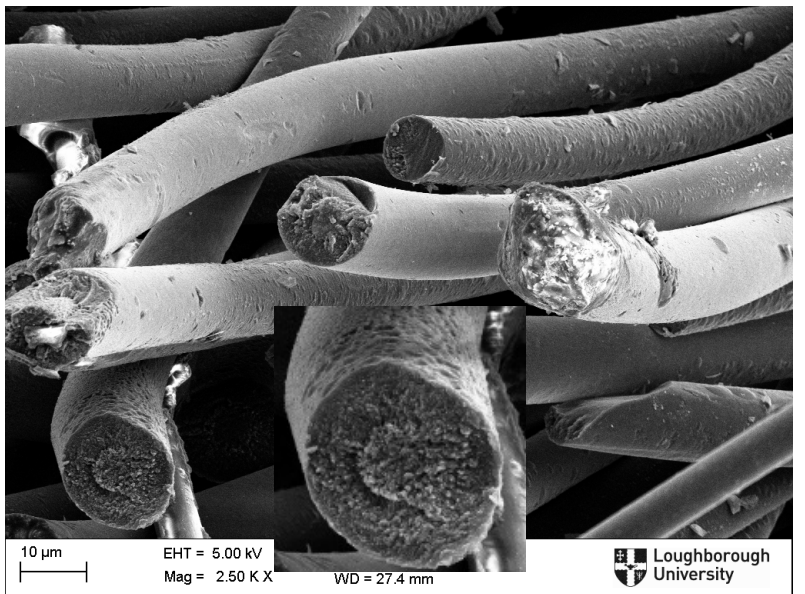

(a)

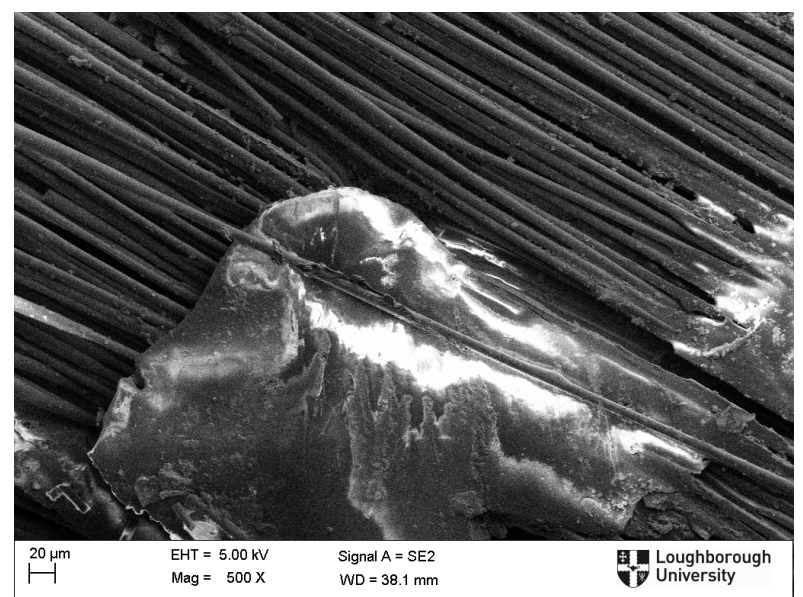

(c)

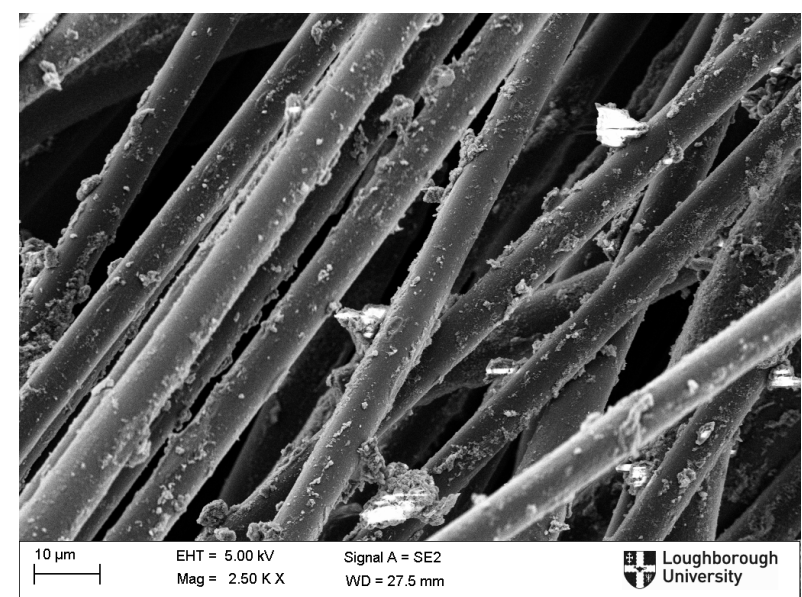

(b)

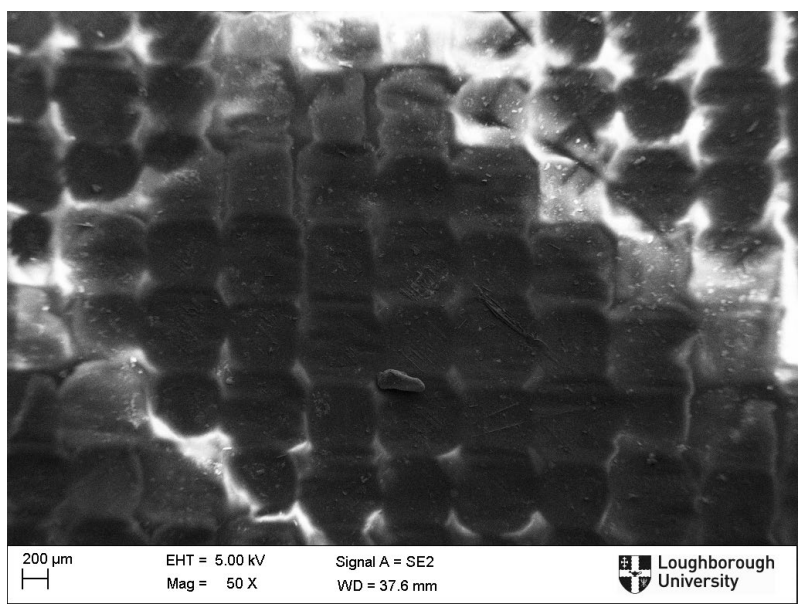

(d)

Figure 9 Micrographs of (a) Panel 3-5 Location 1, (b) Panel 3-5 Location 2, (c) Panel 3-6 Location 4 and (d) Panel 3-6 Location 6. 
An atomic element analysis via EDS on a scanned surface area of about $0.25 \mu \mathrm{m}^{2}$ from strategically selected locations revealed the presence of carbon, oxygen, hydrogen, chlorine, silicon, sulphur and nitrogen. Only carbon and oxygen elements were shown to have more than one weight percentage, whereas the rest were just traces. Figures $10 \mathrm{a}$ and $10 \mathrm{~b}$ show the respective weight percentage variations of carbon and oxygen with location from Panels 3-4 and 3-5. The steady decrease of carbon concentration with the radial location in Figure 10a is very much expected, as the intensive Joule heating in the central zone locations released oxygen from the samples, leaving the areas being dominated by carbon. In addition, there was a good chance that the scanned areas at Locations 1 and 2 were on the surfaces of carbon filament shafts. On the contrary, the steady increase in oxygen concentration is also expected, as shown in Figure 10b, in which towards the undamaged areas carbon percentage decreased and oxygen percentage increased.

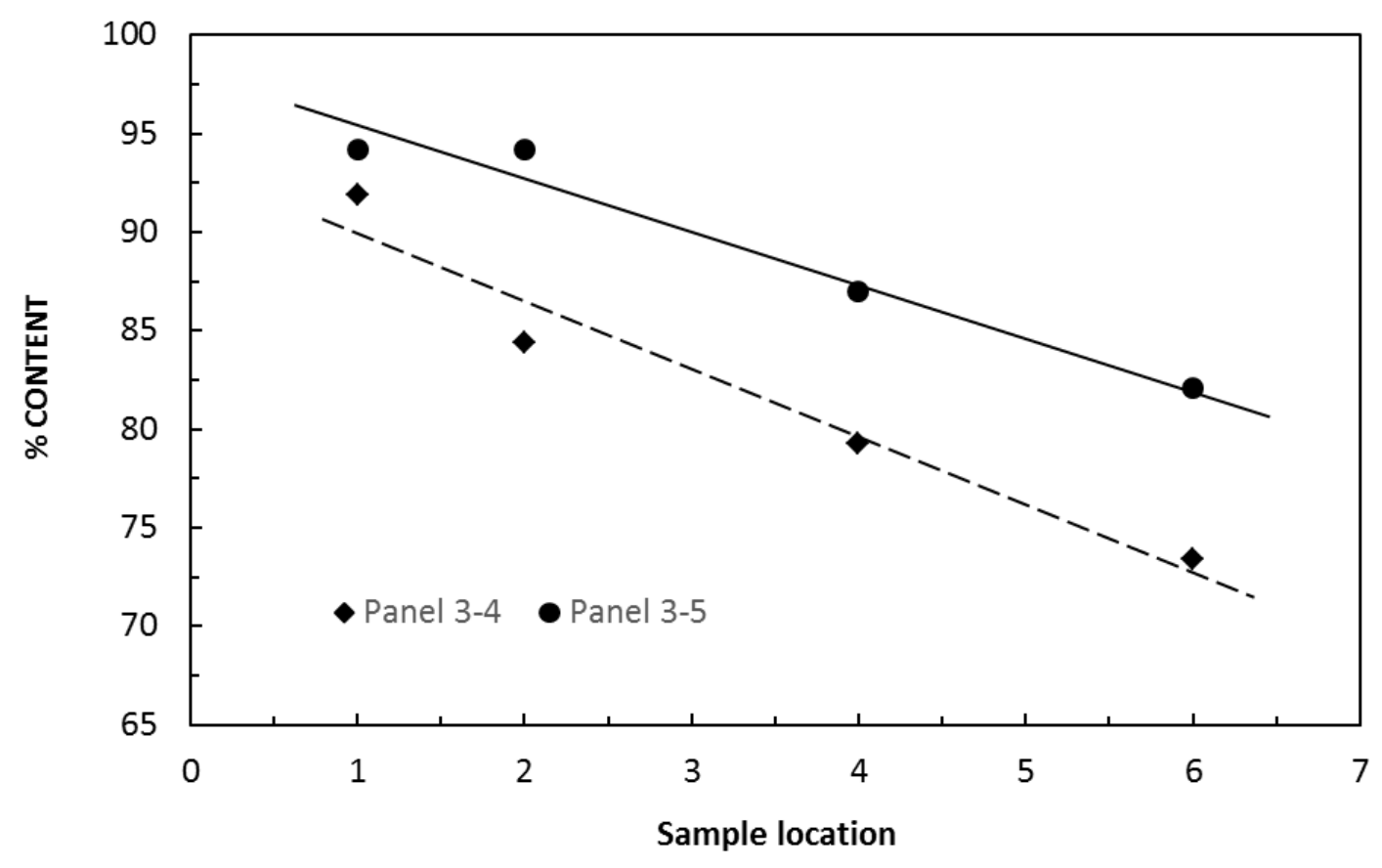

Figure 10a Percentage variation of carbon content along the locations.

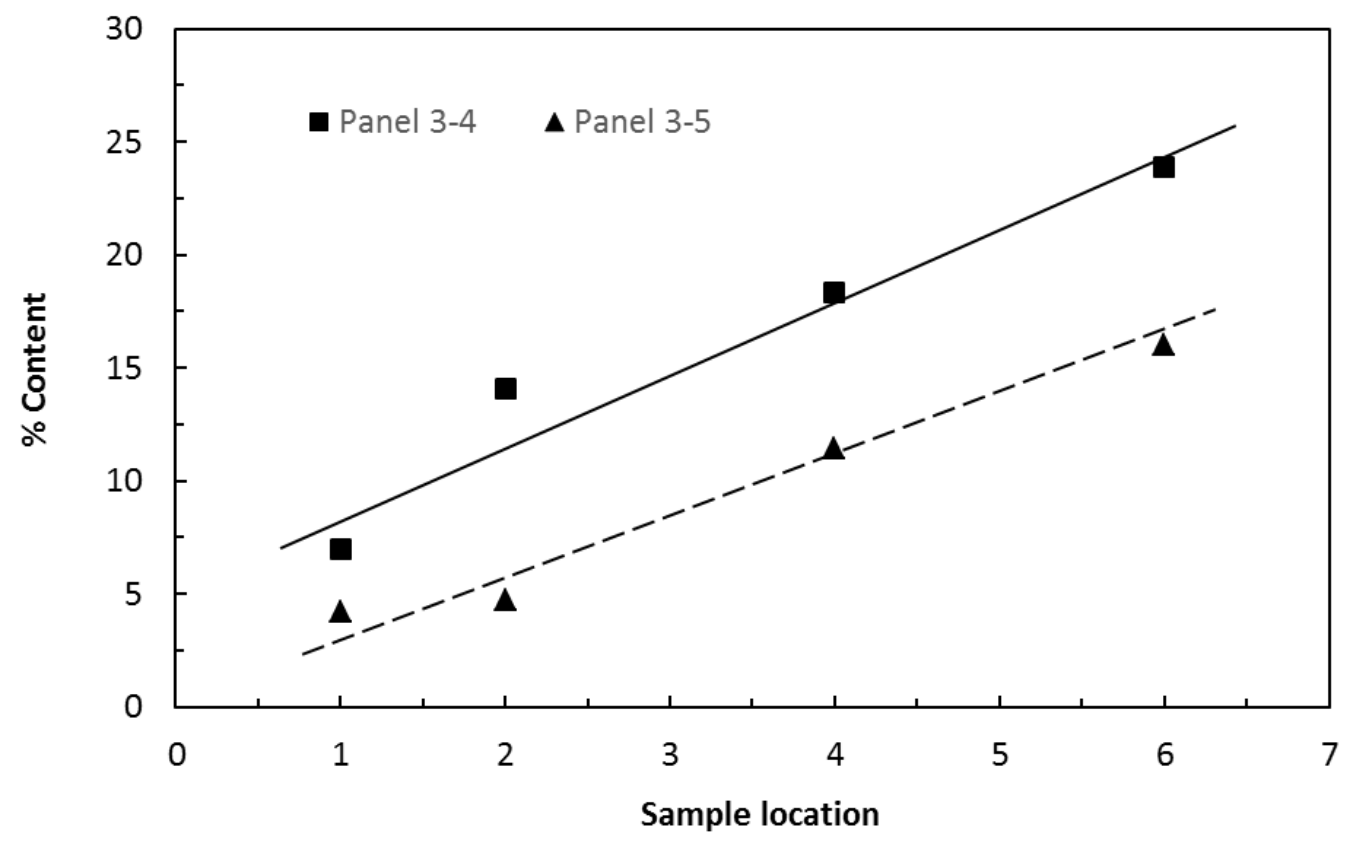

Figure 10b Percentage variation of oxygen content along the locations. 
A series of FTIR-ATR examinations was performed at each of the strategically selected locations on each panel to evaluate comparatively the chemical functional groups either thermally formed/modified or released after Joule heating. Figures $11 \mathrm{a}$ and $11 \mathrm{~b}$ show mid-infrared spectra from the two separate undamaged areas at Locations 6 and 7 on Panel 3-4 and demonstrate good consistency and repeatability. There are around 29 absorption bands or peaks with strong or moderate intensity across both the functional group and fingerprint regions. They were assigned to compounds with letters, as listed in Table 2. Figure 12 shows a spectrum from a thermally damaged area (Location 3) on Panel 3-5, in which some fibre filaments were exposed. For the fingerprint regions of both panels from 1450 to $600 \mathrm{~cm}^{-1}$, there was no new compound being formed thermally, which confirmed the chemical composition of the carbon/epoxy material by comparing the identified peaks at the same wave numbers. In the functional group regions of both spectra, the most intense peaks occurred towards the two ends of the regions, namely, between 3900 and $3000 \mathrm{~cm}^{-1}$ and between 2100 and $1500 \mathrm{~cm}^{-1}$, respectively. Three additional peaks between 3000 and $2100 \mathrm{~cm}^{-1}$ were identified from the damaged sample in Figure 12. Large broad peaks (Peaks a-c) between $3900 \mathrm{~cm}^{-1}$ and $3600 \mathrm{~cm}^{-1}$ were likely to be from secondary alcohol groups containing hydroxyl with an $\mathrm{O}-\mathrm{H}$ bond. Multiple sharp narrow peaks between $3550 \mathrm{~cm}^{-1}$ and $3400 \mathrm{~cm}^{-1}$ with moderate intensities could be from amino groups with an $\mathrm{N}-\mathrm{H}$ bond. Multiple peaks between $2100 \mathrm{~cm}^{-1}$ and $1500 \mathrm{~cm}^{-1}$ were dominated by acetylene and ketone containing $\mathrm{C} \equiv \mathrm{C}$ and $\mathrm{C}=\mathrm{O}$ bonds. Carbonyl groups held two characteristic peaks ( $\mathrm{s}$ and $\mathrm{t}$ in Table 2) in the region of $1850-1600 \mathrm{~cm}^{-1}$ with a $\mathrm{C}=\mathrm{O}$ bond for ketone. Phenols, cresols, aldehydes, isopropenyl phenols and bisphenol A appeared among the decomposed residues from both cases, as in [14].

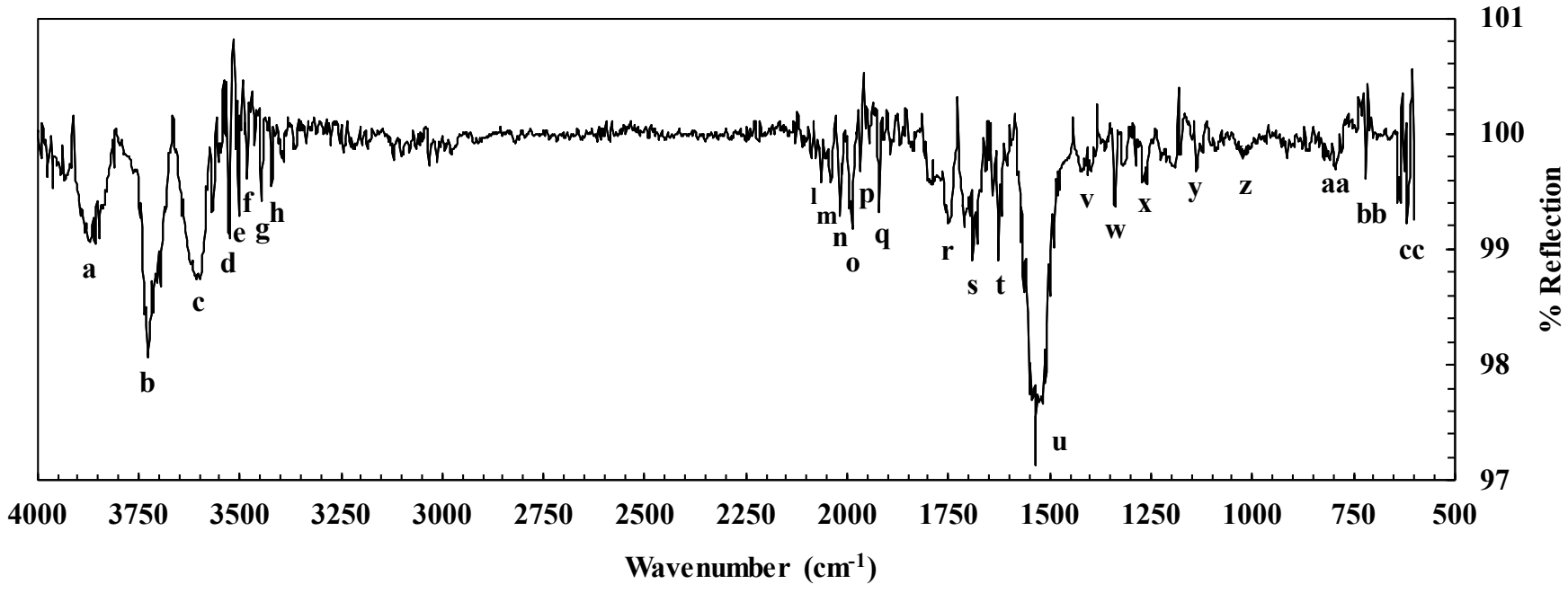

Figure 11a A FTIR-ATR spectrum from an undamaged Location 6 on Panel 3-4.

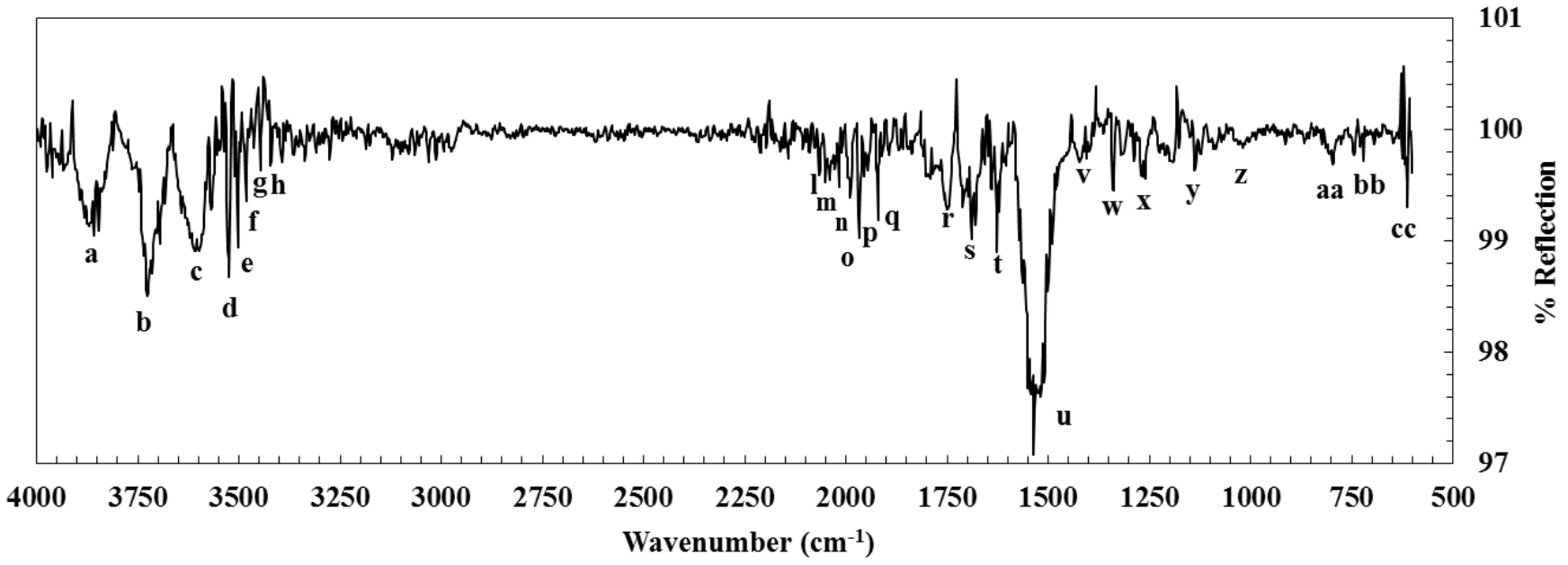

Figure 11b A FTIR-ATR spectrum from an undamaged Location 7 on Panel 3-4. 
Table 2 Chemical functional groups of carbon/epoxy identified in FTIR-ATR spectra

\begin{tabular}{|c|c|c|c|c|c|}
\hline Peak ID & Wave number & $\begin{array}{l}\text { Peak } \\
\text { status }\end{array}$ & $\begin{array}{c}\text { Chemical functional } \\
\text { group }\end{array}$ & $\begin{array}{c}\text { Bond and } \\
\text { vibrational mode } \\
\end{array}$ & $\begin{array}{c}\text { Bond dissociation } \\
\text { energy } \mathrm{kJ} / \mathrm{mol}\end{array}$ \\
\hline $\mathbf{a}, \mathbf{b}, \mathbf{c}$ & $3875,3725,3600$ & B & Hydroxyl, alcohol & $\mathrm{O}-\mathrm{H}$ stretch & $426[13]$ \\
\hline $\mathbf{d}, \mathbf{e}, \mathbf{f}, \mathbf{g}$ & $3525,3500,3480,3450$ & B & Aromatic amine & N-H stretch & $386[12]$ \\
\hline h & 3420 & UD & Aromatic amine & N-H stretch & $386[12]$ \\
\hline $\mathbf{i}$ & 2925 & $\mathrm{D}$ & Aromatic aldehyde & C-H stretch & $472[12]$ \\
\hline $\mathbf{j}$ & 2850 & $\mathrm{D}$ & Aliphatic aldehyde & C-H stretch & 374 [12-13] \\
\hline $\mathbf{k}$ & 2160 & $\mathrm{D}$ & Acetylene & $\mathrm{C} \equiv \mathrm{C}$ stretch & $966[13]$ \\
\hline 1 & 2060 & UD & Acetylene & $\mathrm{C} \equiv \mathrm{C}$ stretch & 837 [13] \\
\hline $\mathbf{m}$ & 2040 & $\mathrm{~B}$ & Acetylene & $\mathrm{C} \equiv \mathrm{C}$ stretch & 837 [13] \\
\hline $\mathbf{n}, \mathbf{o}, \mathbf{p}, \mathbf{q}$ & $2020,1990,1970,1925$ & UD & Aromatic overtone & $\mathrm{C}=\mathrm{C}$ stretch & $611[14]$ \\
\hline $\mathbf{r}$ & 1750 & UD & Aliphatic aldehyde & $\mathrm{C}=\mathrm{O}$ stretch & $741[12]$ \\
\hline $\mathbf{s}$ & 1690 & UD & Carbonyl, ketone & $\mathrm{C}=\mathrm{O}$ stretch & 745 [12] \\
\hline $\mathbf{t}$ & 1625 & $\mathrm{~B}$ & Carbonyl, ketone & $\mathrm{C}=\mathrm{O}$ stretch & 745 [12] \\
\hline $\mathbf{u}$ & 1540 & B & Aromatic amine & $\mathrm{C}-\mathrm{N}$ bend & $436[12]$ \\
\hline $\mathbf{v}$ & 1410 & B & Aliphatic aldehyde & $\mathrm{C}-\mathrm{C}$ bend & 355 [12-13] \\
\hline $\mathbf{w}$ & 1340 & UD & Aromatic ketone & C-C stretch & 413 [13] \\
\hline $\mathbf{x}$ & 1260 & $\mathrm{~B}$ & Aromatic ketone & C-C stretch & 413 [13] \\
\hline $\mathbf{y}$ & 1140 & UD & Aliphatic aldehyde & $\mathrm{C}-\mathrm{H}$ bend & 374 [12-13] \\
\hline $\mathbf{z}$ & 1025 & $\mathrm{~B}$ & Alkyl aryl ether & C-O-C stretch & $351[13]$ \\
\hline aa & 800 & B & Aromatic & C-H bend & 332 [12] \\
\hline bb & 670 & B & Alkene & $\mathrm{C}-\mathrm{H}$ bend & $463[13]$ \\
\hline cc & 610 & B & Aliphatic ether & $\mathrm{C}-\mathrm{H}$ bend & $389[13]$ \\
\hline
\end{tabular}

* B - Unchanged; D - New in damaged panel; UD - Significantly reduced in damaged panel.

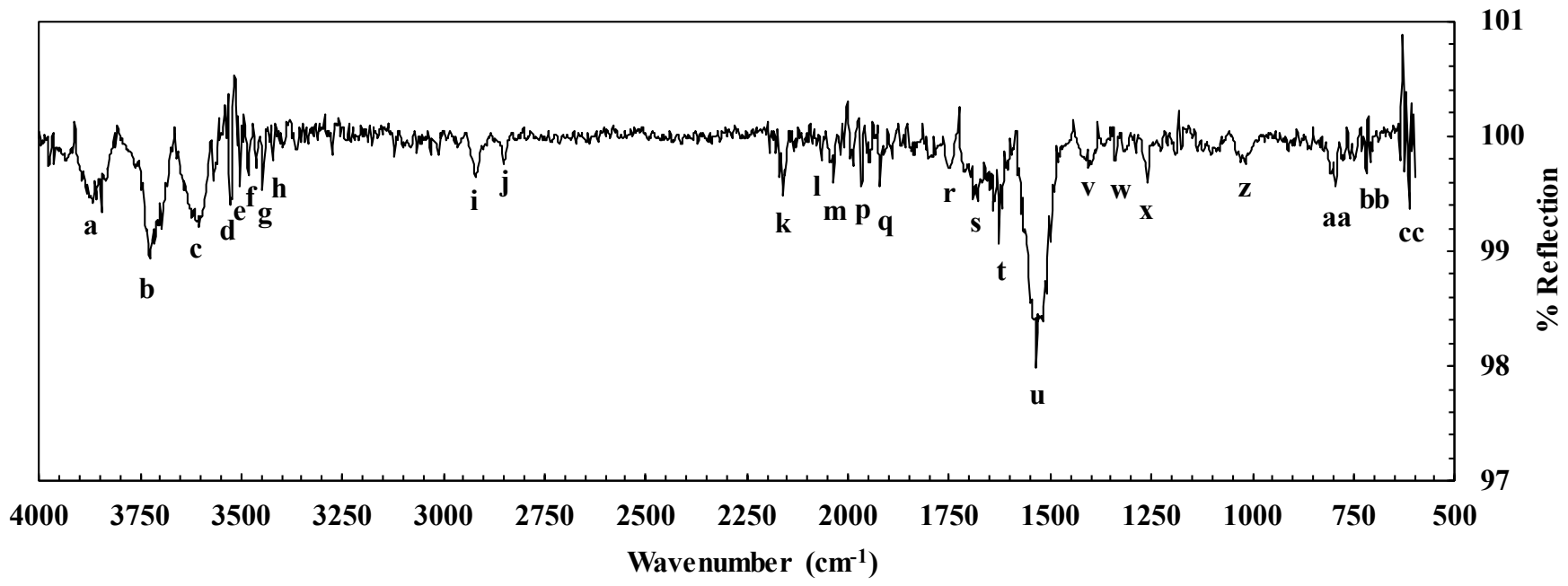

Figure 12 A FTIR-ATR spectrum from a thermally damaged Location 3 on Panel 3-5.

Those three additional peaks (Peaks i, j and $\mathrm{k}$ in Table 2) from the damaged sample between 3000 and $2100 \mathrm{~cm}^{-1}$ in Figure 12 were not present in Figures $11 \mathrm{a}$ and $11 \mathrm{~b}$ and did not appear to be from any one of the cure linkages. These species could be generated through the thermal heating associated with the lightning strike. Dehydration could release oxygen as shown in Figure 10b, via the removal of hydroxyl groups. The appearance of carbonyl was parallel with the decrease of hydroxyl [14]. 


\subsection{Destructive TGA of pristine composite samples}

TGA thermograms in terms of residual weight and temperature derivative reflect the thermal degradation, decomposition and vapourisation of fragments broken off due to the chain scission of molecular bonds of DGEBA-DDM epoxy resin. Figure 13 shows such thermal processes from pristine composite samples in nitrogen. A residual weight in a sigmoidal path is initially linear and slow, then becomes rapid in a relatively narrow temperature range and finally levels off with some residual at the limit temperature of $800^{\circ} \mathrm{C}$. The average initiation temperature of $343^{\circ} \mathrm{C}$ corresponded to the weight loss of less than $1 \%$ from the composite but of around $3 \%$ from resin. At the average peak temperature of $405^{\circ} \mathrm{C}$ where the average maximum rate of decomposition occurred, the respective weight losses were about $11 \%$ of the composite and about $38 \%$ of resin. At the average final temperature of $463^{\circ} \mathrm{C}$, the respective weight losses were about $21 \%$ for the composite and about $70 \%$ for resin. Even at $800^{\circ} \mathrm{C}$, there were still some residual fragments remaining with the amount varying from $4 \%$ up to $17 \%$. These results are consistent with other reported evapouration temperature values between $400^{\circ} \mathrm{C}$ and $440^{\circ} \mathrm{C}$ for DGEBA resins [15]. In addition, these TGA thermograms demonstrate excellent consistency and repeatability.

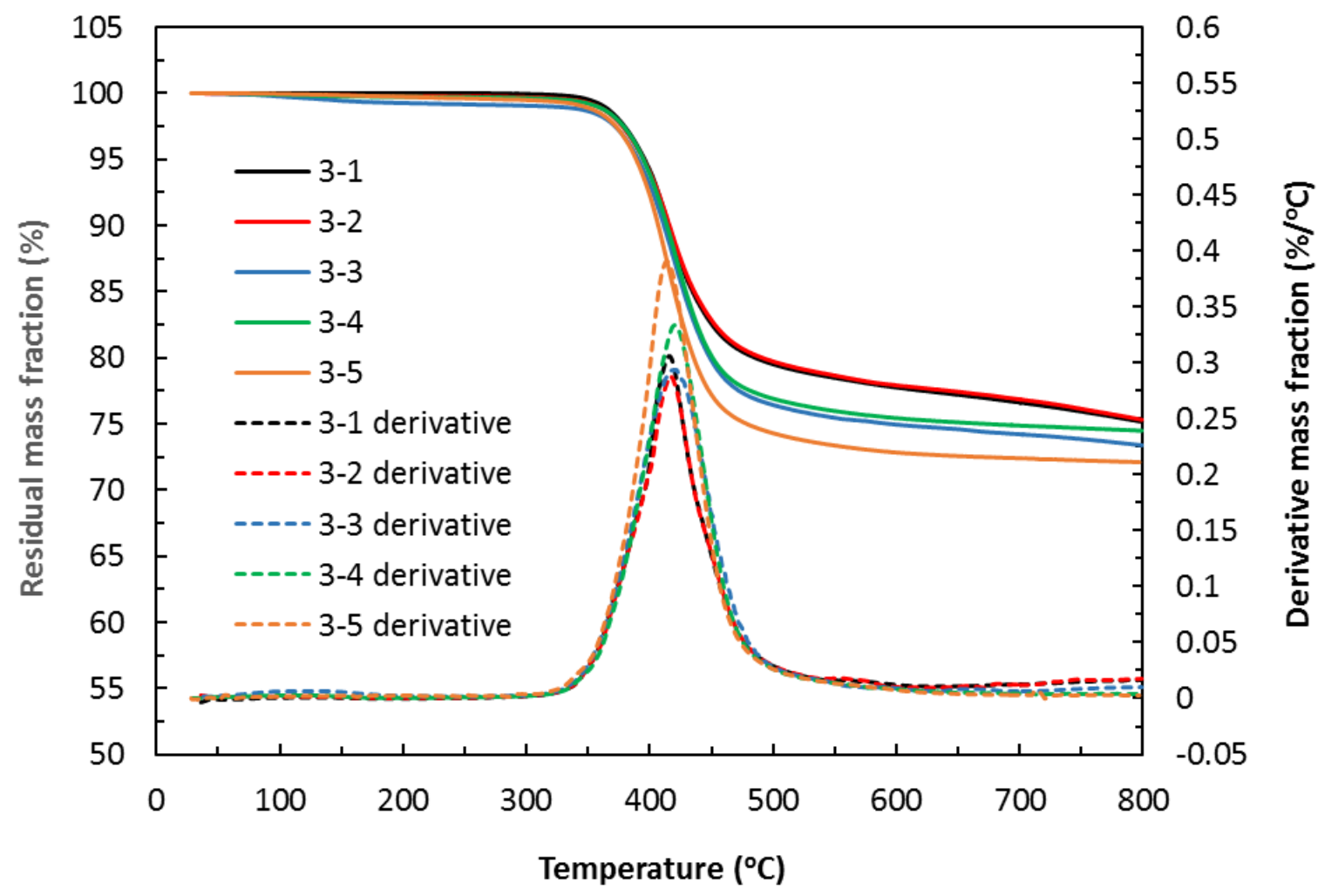

Figure 13 TGA thermograms from pristine samples (Location 7) of five panels in nitrogen at the heating rate of $20^{\circ} \mathrm{C} / \mathrm{min}$.

The effect of the moderately increasing heating rate on the characteristic temperatures in Figure 4 was small. Thus, the dependence of the maximum reaction rates on the heating rates was small and the limited increase of heating rate could have delayed the kinetics of the thermal decomposition but did not modify the nature of the process. Nevertheless, at the heating rate of $5^{0} \mathrm{C} / \mathrm{min}$, there was another noticeable stage of weight loss accelerating from $590^{\circ} \mathrm{C}$ onwards and as the heating rate was increased up to $20^{\circ} \mathrm{C} / \mathrm{min}$, this stage disappeared. This weight loss could correspond to the partial decomposition and vapourisation of the silane coating of carbon fibres. These observations, as shown in Figure 5, become more obvious when similar carbon/epoxy samples were tested in air where about $19 \%$ oxygen became available from the environment. Further TGA thermograms, shown in Figure 
14 , from pristine samples tested in air at the heating rate of $20^{\circ} \mathrm{C} / \mathrm{min}$ demonstrate good consistency and repeatability.

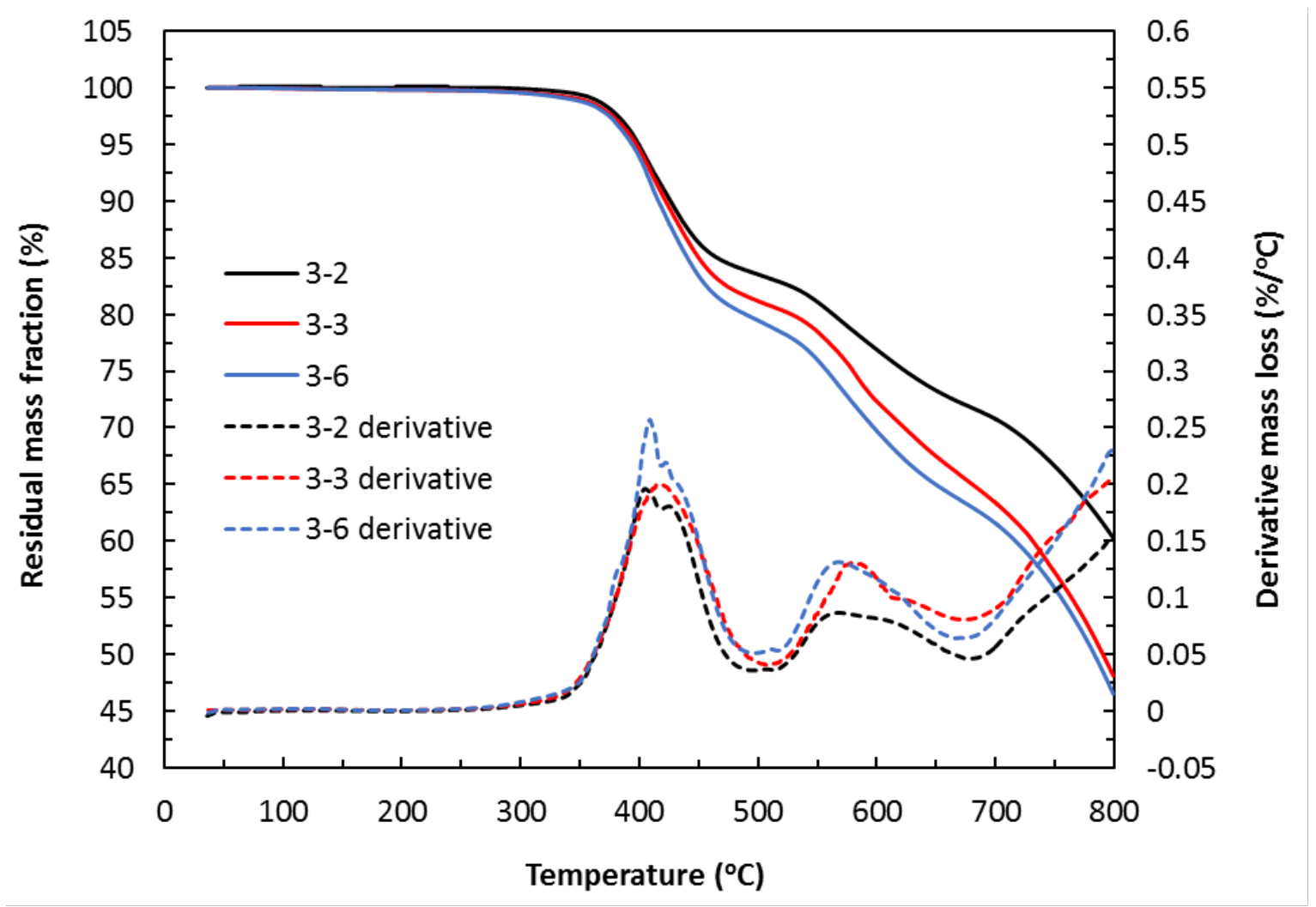

Figure 14 TGA thermograms from pristine samples (Location 7) of three panels in air at the heating rate of $20^{\circ} \mathrm{C} / \mathrm{min}$.

\subsection{Composite samples with thermal histories}

As illustrated in Figures 3 and 8, composite samples extracted from three damage zones on each of six panels represented each of all three damage states of thermal history, being dominated by fibre tufting, exposed fibre tows and resin discolouration. These damage characteristics occupied only about 38\% (3 plies deep), 20\% ( 2 plies deep) and 10\% (one ply deep) of the total sample volumes. In addition, resin discolouration in Damage Zone 3 was driven by convection due to the outward spreading of the diverted lightning plume. Thus, the overall sigmoidal shapes of the thermal responses of these samples are similar to those of pristine samples. Figure 15 shows the effects of the damage state characteristics on the average TGA peak temperature from all three heating rates. Since the Location 1 samples contained the least amount of resin to decompose, they thus provided the greatest pyrolysis resistance. As a result, from Locations 1 to 4 , the average peak temperatures decrease steadily. Between Locations 4 and 7, samples from the former location had just one face being discoloured and hence a small difference could not be reflected by the average peak temperatures, when compared to those from the undamaged locations. Resin discolouration was associated with dehydration, which corresponded to less than $3 \%$ resin weight loss. Therefore, the lesser resin allowed the greater heat infiltration to achieve the greater temperature at the same residual weight.

\subsection{Mechanisms of degradation and decomposition}

The short-term thermal degradation and decomposition depended on the functionality of epoxide monomers, curing agents and cure linkages, in addition to temperature and its reaction rate, as carbon fibres did not contribute much to the reactions of the epoxy up to about $600^{\circ} \mathrm{C}$. Although the thermal 
heating associated with lightning strikes lasted only a very short duration, the fact that it occurred in air could still mean that oxygen may make some contributions so that the decomposition process could not be completely non-oxidative. Once heated beyond glass transition temperature and when the rate of heat dissipation fell behind the rate of heat injection, epoxy resin in the cross-linked network went, in part, through multiple complex scission schemes of chemical bonds via dehydration, decomposition and sublimation with increasing temperatures well before that of carbon fibres. As a highly cross-linked molecular structure severely hindered the movement of any part of the network relative to one another, the tentative degradation schemes proposed were largely limited to the scission of chemical bonds in the network. These schemes started from side chains and delocalisation and followed with weak cure links from the main chains of epoxy resin to generate fragments, all of which were influenced by their relative magnitudes of bond dissociation energies.

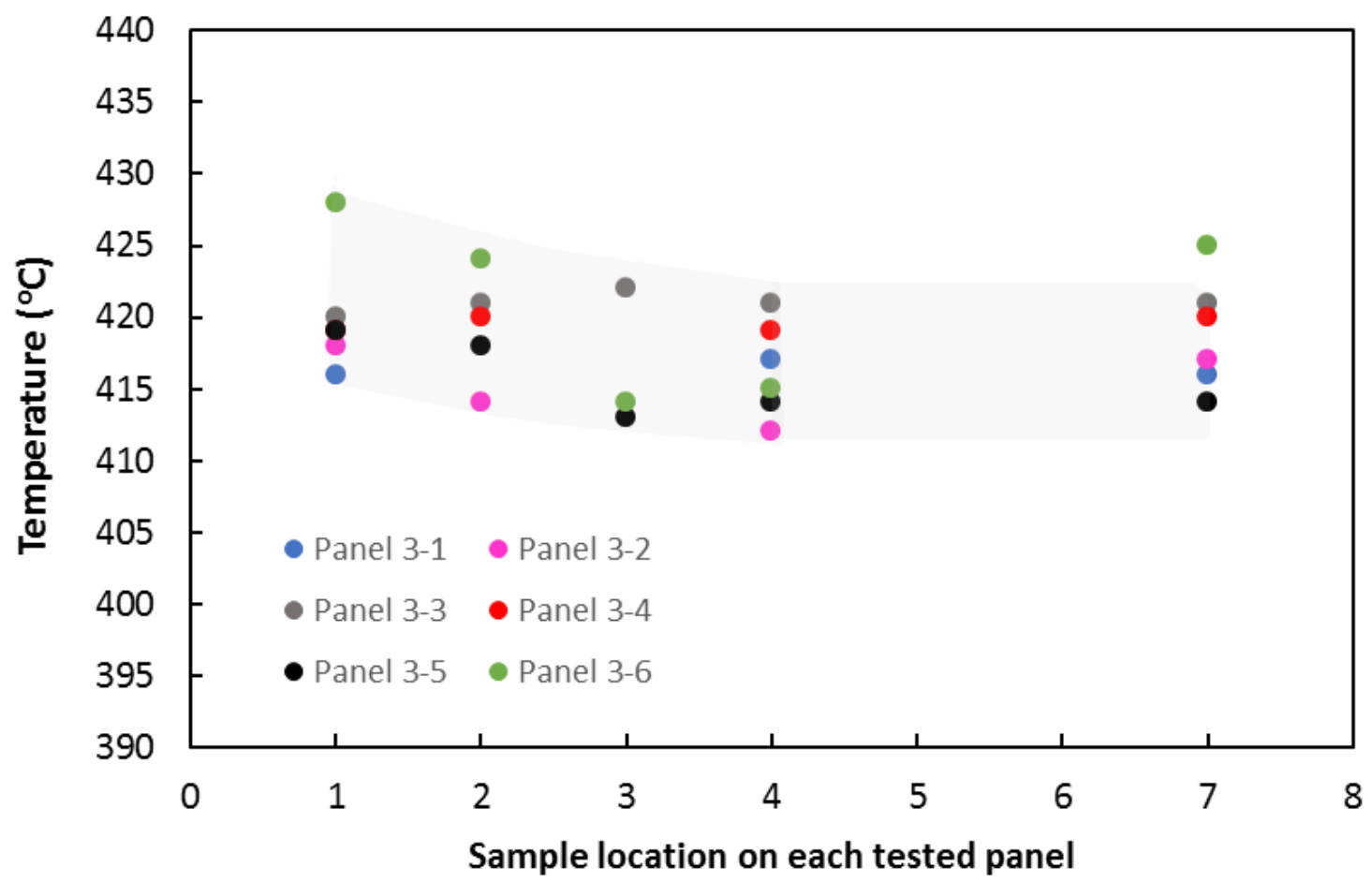

Figure 15 Variation of peak temperature with the sample location.

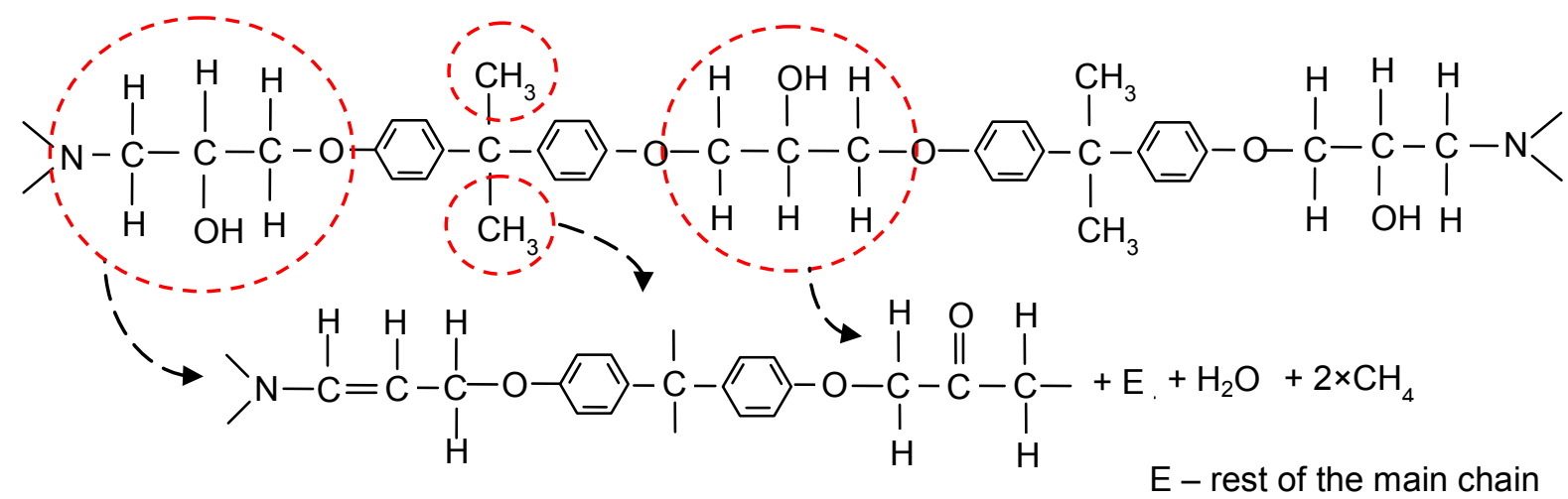

Figure 16 Dehydration schemes in heated carbon/DGEBA-DDM epoxy composite samples.

Dehydration in pristine composite samples started from $120^{\circ} \mathrm{C}$ to $343^{\circ} \mathrm{C}$ from secondary alcohol groups due to delocalisation, and a break-up of the hydroxyl group and methyl group of bisphenol A off the main chain, as indicated through a recurring segment of the cross-linked DGEBA-DDM network in Figure 16. These cleavages formed water and released methane, which were widely 
reported in [14-19]. Moreover, dehydration led to the formation of carbonyl with $\mathrm{C}=\mathrm{O}$ double bond and alcohols tended to have the alpha cleavage next to the carbon, which bore the hydroxyl group. This proposed dehydration scheme was also corroborated by the earlier findings of elemental analysis in Figures 10a-10b, in which carbon content increased from the undamaged zone (Location 6 ) to the damaged one, whereas oxygen decreased. Dehydration that corresponded to around $1 \%$ weight loss resulted physically in the yellowish discolouration appearance, with no other detectable degradation fragments as also reported in [16] at $350^{\circ} \mathrm{C}$. The formation of a pseudo conjugation between $\mathrm{C}=\mathrm{O}$ and $\mathrm{C}=\mathrm{C}$ double bonds could also contribute to the resin discolouration in [17]. Dehydration led to densification and embrittlement so that dehydrated resin could be prone to brittle fracture at a much lower mechanical load, though some argued [18] that chemical reactions could occur either before or concurrently with dehydration.

The intensified thermal heating at the dehydrated Zones 1 and 2 led not only to cleavages of the main chain and eventual sublimation of species but also to an outward spreading of dehydration (to Zone 3). The cleavage of the dehydrated main chain from $343^{\circ} \mathrm{C}$ to $405^{\circ} \mathrm{C}$ depended primarily on the relative values of dissociation energy of the functional groups (as indicated in Table 2). As proposed in Figure 17 (via a red dashed line, with single-dotted dash and double-dotted dash lines as cleavage alternatives), the $\mathrm{N}-\mathrm{C}$ bond, as a cure linkage, was the weakest on the main chain. That was followed by $\mathrm{C}-\mathrm{C}$ and $\mathrm{C}-\mathrm{O}$ bonds, especially between allylic carbon and phenoxy oxygen, as their respective bond dissociation energies were relatively low [19]. Functional groups containing benzene rings tend to cleave at the carbon next to the ring. Common identifiable compounds included phenol and isopropyl phenol, $p$-toluidine, 2-propenal, $p$-cresol, ketone, amine, aliphatic and aromatic aldehydes, propylene and allyl phenyl ether in addition to methane, $\mathrm{CO}_{2}$ and $\mathrm{CO}$. Some of these species such as allyl phenyl ether and isopropyl phenol, under the increasing temperatures, were speculated to undergo further decomposition (blue arrows in Figure 17) to acetylene, acetaldehyde, aromatic aldehyde and aromatic ether, among others. These compounds were also identified in [14-16,19] for DGEBA-DDM resins at different temperatures. Among them, 2-propenal, acetylene and aromatic ether that appeared at specific IR bands could be viewed as the unique groups of the thermal degradation and decomposition, as they could be formed only through the thermal heating. Resin sublimation via some of those volatiles started from $343^{\circ} \mathrm{C}$ and was accompanied by the steady increase in weight loss. This process continued up to the peak temperature and beyond. The sublimation of carbon fibre coating started beyond $510^{\circ} \mathrm{C}$, as shown in Figure 5.

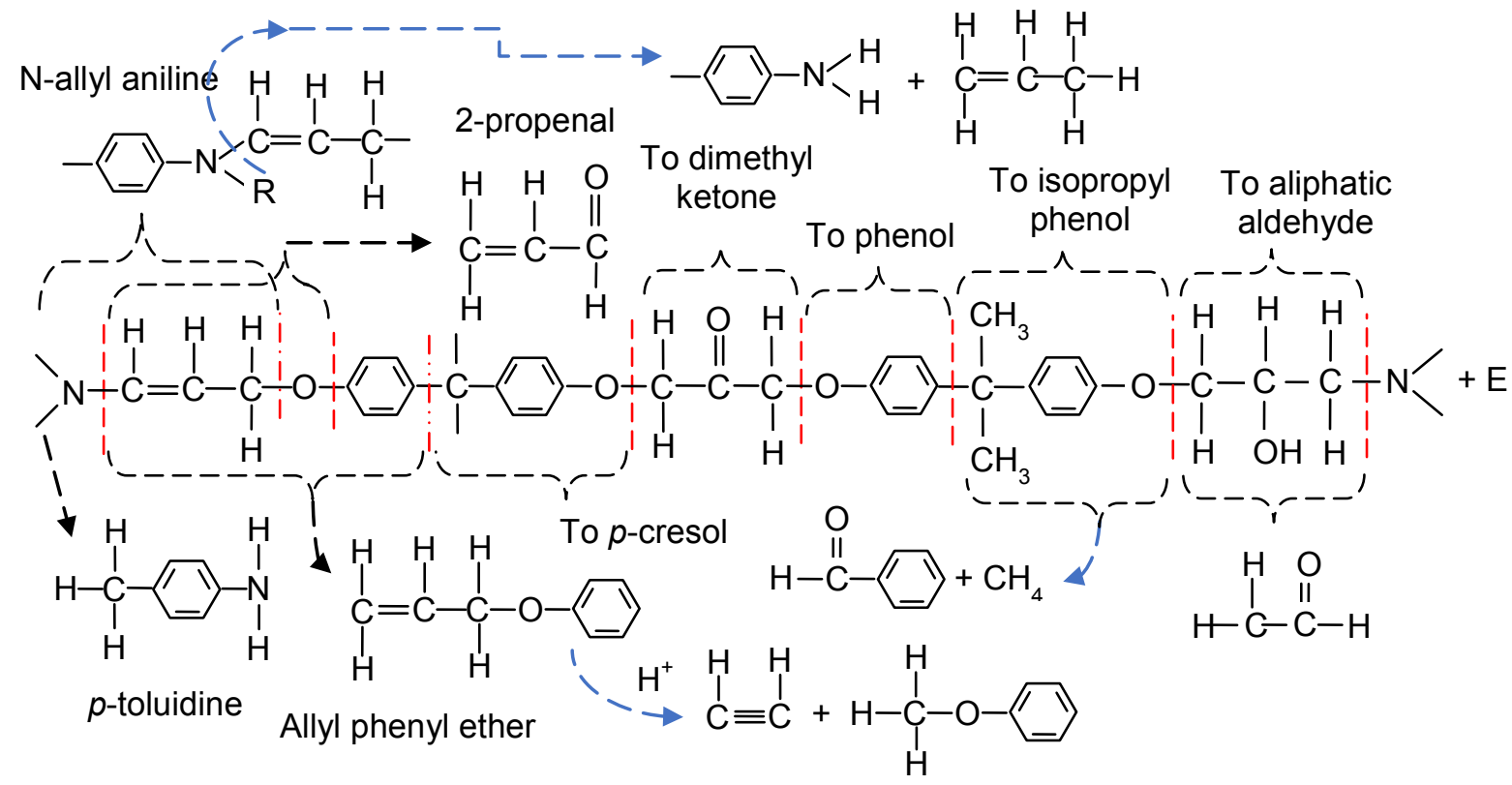

Figure 17 Proposed thermal decomposition schemes in carbon/epoxy composite samples. 


\section{Conclusions}

The damage state characteristics at multiple selected locations, representing three damage zones, on each of six carbon/epoxy panels were examined non-destructively using SEM and FTIR. Samples extracted from the examined locations were tested destructively using TGA. Through damage state comparisons and forensic reconstruction of samples from different locations on the same panels and the same locations on different panels, fibre tufting (in the central damage Zone 1) was found to be caused by returning shock waves, rather than thermal sublimation, whereas partial resin sublimation (exposing fibre tows) and discolouration in the two outer annular damage zones were dominated by the thermal degradation. The carbon concentration was found to decrease steadily away from the panel centre, whereas oxygen increased, and was in accordance with the trend of the peak temperatures of TGA tests.

The proposed scission schemes of chemical bonds in epoxy were found to start from dehydration, accompanied by discolouration, due to a delocalisation of alcohol groups and a break-up of hydroxyl and methyl groups on the side chains. These cleavages formed water and carbonyl and released methane during dehydration. Further decomposition mechanisms from the dehydrated main chain from $343^{\circ} \mathrm{C}$ to $405^{\circ} \mathrm{C}$ followed, with the cleavages of weak $\mathrm{N}-\mathrm{C}$ cure link, $\mathrm{C}-\mathrm{C}$ and $\mathrm{C}-\mathrm{O}$ bonds, especially between allylic carbon and phenoxy oxygen. Common identified compounds, 2-propenal, acetylene and aromatic ether containing carbonyl could be viewed as the unique groups of the thermal degradation, as they could be formed only through the thermal heating. These proposed schemes were corroborated by the elemental analysis results and appeared at specific IR bands.

The key degradation characteristics and established decomposition mechanisms provided a deeper insight into the understanding of the degradation processes and decomposition mechanisms in composite samples. With consistent and repeatable results for the same material states, they paved the way for ultimately establishing a post-mortem solid residual-based thermal damage characterising methodology. Part of the present findings was based on the results of a few TGA tests of the damaged samples. In the future, a larger number of damaged TGA samples along with more TGA testing in air could be included to improve data accuracy.

\section{Acknowledgments}

The first author would like to acknowledge the financial support from the 2011 Loughborough University/EPSRC-Bridging the Gaps Networking grant. The lightning strike testing assistance from Messrs Z. Wang and X. Zhang from C-Power Ltd are also acknowledged.

\section{References}

[1] Dong Q, Guo Y, Sun X, Jia Y. Coupled electrical-thermal-pyrolytic analysis of carbon fiber/epoxy composites subjected to lightning strike. Polymer 2015;56:385-394.

[2] Wang F, Ji Y, Yu X, Chen H, Yue Z. Ablation damage assessment of aircraft carbon fiber/epoxy composite and its protection structures suffered from lightning strike. Composite Structures 2016;145:226-241.

[3] Allheily V, Lacroix F, Eichhorn A, Merlat L, L'Hostis G, Durand B. An experimental method to assess the thermo-mechanical damage of CFRP subjected to a highly energetic $1.07 \mathrm{~mm}$ wavelength laser irradiation. Composites Part B 2016;92:326-331.

[4] Uhlmann E, Spur G, Hocheng H, Liebelt S, Pan CT. The extent of laser-induced thermal damage of UD and crossply composite laminates, Int $\mathbf{J}$ of Machine Tools and Manufacture 1999;39:639-650.

[5] Tranchard P, Duquesne S, Samyn F, Estebe B. Kinetic analysis of the thermal decomposition of a carbon fibre-reinforced epoxy resin laminate. J Anal and Appl Pyrolysis 2017;126(C):14-21. 
[6] Quintiere JG, Walters, RN, Crowley S. Flammability properties of aircraft carbon-fiber structural composite. DOT/FAA/AR-07/57-TR 2007.

[7] Liu Y, Liu J, Jiang Z, Tang T. Chemical recycling of carbon fibre reinforced epoxy resin composites in subcritical water: synergistic effect of phenol and $\mathrm{KOH}$ on the decomposition efficiency. Polymer Degradation and Stability 2012;97:214-220.

[8] Vyazovkin S, Chrissafis K, Di Lorenzo ML, Koga N, Pijolat M, Roduit B, Sbirrazzuoli N, Suñol JJ. ICTAC kinetics committee recommendations for collecting experimental thermal analysis data for kinetic computations. Thermochimica Acta 2014;590:1-23.

[9] Morelli JJ. Thermal analysis using mass spectrometry - a review. J of Anal and Appl Pyrolysis 1990;18:1-18.

[10] Ferdosian F, Yuan Z, Anderson M, Xu C. Thermal performance and thermal decomposition kinetics of lignin-based epoxy resins. J of Anal and Appl Pyrolysis 2016;119:124-132.

[11] Lee YF, Dollimore D. The identification of the reaction mechanism in rising temperature kinetic studies based on the shape of the DTG curve. Thermochimica Acta 1998;323:75-81.

[12] Luo Y. Comprehensive handbook of chemical bond energies, CRC Press, Boca Raton, 2007.

[13] Blanksby S, Ellison G. Bond dissociation energies of organic molecules. Accounts of Chemical Research 2003;36:255-263.

[14] Lee L. Mechanisms of thermal degradation of phenolic condensation polymers. II. Thermal stability and degradation schemes of epoxy resins. J Polymer Sci Part A 1965;3:859-882.

[15] Madorsky SL, Straus S. Stability of thermoset plastics at high temperatures. Modern Plastics 1967;38:134-140.

[16] Bishop DP, Smith DA. Combined pyrolysis and radiochemical gas chromatography for studying the thermal degradation of epoxy resins and polyimides I. the degradation of epoxy resins in nitrogen between $400^{\circ} \mathrm{C}$ and $700^{\circ} \mathrm{C}$. J Appl Polymer Sci 1970;14:205-223.

[17] Wade LG, Simek JW. Organic Chemistry, 9th Edition. Pearson, New York 2017.

[18] Paterson-Jones JC, The mechanism of the thermal degradation of aromatic amine-cured glycidal ether-type epoxide resins. J Appl Polymer Sci 1975;19:1539-1547.

[19] Rozenberg BA. Kinetics, thermodynamics and mechanism of reactions of epoxy oligomers with amines. Advances in Polymer Science Part II 1986;75:113-165. 